\title{
Involvement of ROS in the inhibitory effect of thermotherapy combined with chemotherapy on A549 human lung adenocarcinoma cell growth through the Akt pathway
}

\author{
LIN WANG ${ }^{1}$, XINKUI LIU ${ }^{2}$, YONGJUN WU ${ }^{3}$, WEIDONG WU ${ }^{4}$ and YIMING WU ${ }^{3}$ \\ Departments of ${ }^{1}$ Radiotherapy and ${ }^{2}$ Case Management, The First Affiliated Hospital of Zhengzhou University, \\ 450052 Zhengzhou; ${ }^{3}$ College of Public Health, Zhengzhou University, 450001 Zhengzhou, P.R. China; ${ }^{4}$ Center for \\ Environmental Medicine, Asthma and Lung Biology, University of North Carolina, Chapel Hill, NC 27599, USA
}

Received April 1, 2012; Accepted May 31, 2012

DOI: 10.3892/or.2012.1954

\begin{abstract}
Mechanisms of synergistic effect of thermotherapy and chemotherapy on human lung adenocarcinoma cell growth are unclear. The purpose of this study was to investigate these effects and explore the function of ROS, Akt and caspase-3 in relation to these. A549 cells were subjected to different thermochemotherapy treatments: $43^{\circ} \mathrm{C}$ heat $+50 \mu \mathrm{g} / 1$ paclitaxel (thermochemotherapy group), $43^{\circ} \mathrm{C}$ heat $+50 \mu \mathrm{g} / 1$ paclitaxel $+1 \mu \mathrm{mol} / 1$ wortmannin (wortmannin group), $43^{\circ} \mathrm{C}$ heat $+50 \mu \mathrm{g} / \mathrm{l}$ paclitaxel $+30 \mu \mathrm{mol} / 1 \mathrm{NAC}$ (NAC group) and $50 \mu \mathrm{g} / \mathrm{l}$ paclitaxel (chemotherapy group). The cells without any treatment were regarded as controls. Cell proliferation rates were measured with MTT assay and intracellular ROS levels were detected with fluorescence labeling technologies. Phosphorylation of Akt and caspase-3 expression were determined by western blotting and the cell apoptosis rates were examined by flow cytometry. Tests in vivo were carried out at the same time. It was found that the cell proliferation rates of the thermochemotherapy group were significantly lower compared to those of the controls or the chemotherapy group $(\mathrm{P}<0.05)$. The intracellular ROS levels of the thermochemotherapy group were elevated significantly compared with those of other groups, and these changes could be reversed using the ROS inhibitor NAC but not a PI3K inhibitor (wortmannin). Phosphorylation of Akt was significantly decreased in the thermochemotherapy group $(\mathrm{P}<0.05)$, which could be blocked by wortmannin, but increased by NAC $(\mathrm{P}<0.05)$. The caspase- 3 expression levels and cell apoptosis rates of the thermochemotherapy group were higher compared to those of the other groups $(\mathrm{P}<0.05)$. All results have been confirmed by in vivo tests. Thus, the combination of thermotherapy with chemotherapy showed a stronger inhibitory effect on A549
\end{abstract}

Correspondence to: Dr Yiming Wu, College of Public Health, Zhengzhou University, 450001 Zhengzhou, P.R. China E-mail: wuym369@126.com

Key words: A549 cell, ROS, Akt, caspase-3, thermotherapy cell growth compared to chemotherapy alone, which may be able to cause additional cell apoptosis through inhibition of Akt phosphorylation and activation of caspases by increased intracellular ROS production.

\section{Introduction}

Lung cancer is one of the most common malignant tumors worldwide and non-small cell lung cancer accounts for $80 \%$ of all lung cancer cases. Thermotherapy is an approach taking advantage of biological effects of heat to cure tumors. Thermotherapy undergoes a systematic research with the medicine development and equipment advancement (1). Now, thermotherapy is regarded as an effective treatment such as surgery, radiotherapy, chemotherapy and biological treatment (2). In recent years, tumor thermotherapy has been widely used to treat cancer (3), including lung cancer (4). Tumor thermotherapy increased tumor cell sensitivity to drugs in the effective temperature range, reversed tumor cell drugresistance and induce apoptosis (5).

Intracellular ROS could be induced and affected by many factors such as heat, cell cytokines or some chemicals. Its function is to signal to activate cellular apoptosis inducing cell apoptosis pathway (6-9). However, UV radiation was found to be able to lead to increased production of ROS and activation of mitogen activated protein kinase (MAPK) pathway (10). As a member of MAPK family, protein kinase B (PKB)/Akt plays key roles on regulation of cell growth and apoptosis. Phosphorylated Akt (p-Akt) takes part in many physiological and pathological processes directly or indirectly. Activation of Akt pathway showed an obvious promotion on cell growth and was necessary to normal cell growth $(11,12)$. In addition, activated Akt (13), but inactivated cysteinyl aspartate-specific proteinases (caspase) simultaneously were observed in most tumor cells, which might be responsible for tumor occurrence and development (14). Caspase is the core regulatory element in the formation of cell apoptosis regulating network and could be activated by self-catalysis or caspase cascade catalysis. Oxidative stress was able to induce elevated caspase- 3 activation and increased cell apoptosis (15) through degradating more target proteins (16). 
We observed that thermotherapy in combination with chemotherapy showed stronger inhibitory effect on lung tumor cell growth than thermotherapy or chemotherapy alone (17), the molecular mechanisms in the process remained unclear.

\section{Materials and methods}

Cell culture and cell treatments. Human lung adenocarcinoma A549 cell line was purchased from Shanghai Cell Biology Institute Cell Bank, (China) and was cultured in F-12k cell supernatant (Sigma, St. Louis, MO, USA) supplemented with $10 \%$ fetal calf serum (Sigma) at $37^{\circ} \mathrm{C}$ in a $5 \% \mathrm{CO}_{2}$ saturated humidity atmosphere. Logarithmic phase cells were digested with 5\% trypsin solution and the digestion was inactivated in cell supernatant, and then was separated into single cells. The cell density was diluted into $2.5 \times 10^{7}$ cells $/ 1$ and $6 \mathrm{ml}$ of the cell suspension was added into each well of culture plates. Then cells were cultured at $37^{\circ} \mathrm{C}$ in a $5 \% \mathrm{CO}_{2}$ humidified incubator (Heraeus, Germany). After culturing for $24 \mathrm{~h}$, the cells were subjected to different group schemes as follows: cells treated only by $50 \mu \mathrm{g} / \mathrm{l}$ paclitaxel (Taiji Group Sichuan Taiji Pharmacy Co., Ltd., China; the approval number: GY H19994040) were the chemotherapy group while cells treated with $50 \mu \mathrm{g} / \mathrm{l}$ paclitaxel and $43^{\circ} \mathrm{C}$ heat were the thermo-chemotherapy group. Cells in wortmannin (Alexis, USA) group were treated by thermochemotherapy combined with $1 \mu \mathrm{mol} / 1$ wortmannin and cells in NAC (Sigma) group were treated by thermo-chemotherapy combined with $30 \mu \mathrm{mol} / 1 \mathrm{NAC}$. The cells without any treatment were regarded as controls. Hyperthermic treatments were performed by immersing either the culture flasks or parafilm-wrapped 96 -well plates in a waterbath at $43^{\circ} \mathrm{C}$ for $90 \mathrm{~min}$.

MTT assay. Single cell suspension was prepared with the cells in logarithmic phase and cell density was adjusted to $2.5 \times 10^{7}$ cells/l. Then this cell suspension was seeded into 96-well plates, $200 \mu \mathrm{l}$ per well, and cultured at $37^{\circ} \mathrm{C}$ in a $5 \% \mathrm{CO}_{2}$ humidified incubator. After $24 \mathrm{~h}$, cells were treated according to different schemes described above (6-wells were assayed for each group and repeated three times). The treated cells were incubated for $4 \mathrm{~h}$ and $20 \mu \mathrm{l}$ of the solution containing $5 \mathrm{~g} / \mathrm{l} \mathrm{MTT}$ (Sigma) was added to each well and incubation for another $4 \mathrm{~h}$ was performed. MTT was discarded and $150 \mu \mathrm{l}$ dimethylsulfoxide (DMSO) (Takara, China) was added to each well, and then vortexed for $10 \mathrm{~min}$ to dissolve the crystal. DMSO was used as negative control. Absorbance (A) value was measured at $492 \mathrm{~nm}$ with the microplate reader (Sunrise China). Cell proliferation rates were calculated according to the following formula: cell proliferation rate $(\%)=($ average $\mathrm{A}$ value of experimental group/average $\mathrm{A}$ value of control group) $\mathrm{x} 100 \%$.

Intracellular ROS detection. After the treatment was performed, about $1 \times 10^{6}$ cells in the logarithmic growth phase were collected, washed by PBS and centrifuged at $1200 \mathrm{r} /$ $\min$ for $5 \mathrm{~min}$. Then reagent was added and cultured at $37^{\circ} \mathrm{C}$ for $20 \mathrm{~min}$. Intracellular ROS was detected using Reactive Oxygen Species Testing kit (Shanghai Jiemei Gene Medicine Technology Co., Ltd., China). Preservative medium was added and detected at $490 \mathrm{~nm}$ (excitation) and $530 \mathrm{~nm}$ (emission) qualitatively by fluorescence microscope (Olympus, Japan) and quantitatively by F-4500 fluorospectrophotometer (Hitachi, Japan).

Western blotting. Cells in logarithmic phase $\left(1 \times 10^{6}\right)$ (in vitro) or $50 \mathrm{mg}$ tissue (in vivo) from each group were harvested and suspended in cell lysis buffer containing $30 \mathrm{mmol} / 1 \mathrm{NaHCO}_{3}$, $0.1 \mathrm{mmol} / 1 \mathrm{EDTA}, 0.1 \mathrm{mmol} / \mathrm{l} \mathrm{DTT}, 0.5 \mathrm{mmol} / \mathrm{l} \mathrm{PMSF}$ and $2 \mathrm{mg} / \mathrm{l}$ aprotinin. Cells were lysed on ice and centrifuged at $10,000 \mathrm{r} / \mathrm{min}$ and $4^{\circ} \mathrm{C}$ for $10 \mathrm{~min}$. The supernatant and loading buffer was mixed. Equal amount of total protein dissolved in the mixture of each sample was loaded and seperated by sodium dodecylsulfate polyacrylamide gel electrophoresis (SDS-PAGE) (Bio-Rad Laboratories, Hercules, CA, USA) and transferred onto nitrocellulose membrane (Beijing Applygen Technology Ltd., Beijing, China) for antibody blotting. The membrane was incubated with a rabbit monoclonal antibody against Akt (Cell Signaling Technology, Inc., Danvers, MA), a rabbit monoclonal antibody against p-Akt (Ser473) (587F11) (Cell Signaling Technology, Inc.), a rabbit monoclonal antibody against caspase-3 (Cell Signaling Technology, Inc.) or a rabbit monoclonal antibody against $\beta$-actin (Cell Signaling Technology, Inc.) overnight at $4^{\circ} \mathrm{C}$, respectively. After being incubated with goat anti-rabbit IgG antibodies (1:300 dilution) (Beijing Zhongshan Jinqiao Biology Technology Co., Ltd., Beijing, China) for $2 \mathrm{~h}$. The membrane was subjected to immunoblot analysis and the enhanced chemiluminescence method (ECL kit, China) and HRP-DAB kit (Tiangen, Biotech Co., Ltd., Beijing, China) were used to visualize the proteins. $\beta$-actin was used as an internal control. Gel imaging system (Gene Genius, USA) was used to capture images. Semiquantitative values of $\mathrm{p}$-Akt and caspase- 3 were measured by the ratio of the bands of $t-A k t$ and $\beta$-actin.

Cell apoptosis detection. After cell concentration was adjusted, cells were seeded into 50-ml dishes to culture, and then they were treated according to schemes mentioned in cell culture and cell treatments. Cells in each group were suspended as single cells. A total of $1 \times 10^{6}$ cells were collected to tubes, and fixed in ice-cold $70 \%$ ethanol for $12 \mathrm{~h}$ at $4^{\circ} \mathrm{C}$. The ethanol was discarded and cells were digested by $1 \mathrm{ml} 0.5 \%$ typsin (pH 1.5-2.0) for $10 \mathrm{~min}$ and washed with PBS, labeled with propidum iodide (PI) and filtered by 500 -mesh screen to obtain single cell suspension and analyzed directly by FACS 420 flow cytometry (B\&D Systems, USA).

Graft inhibition rates in nude mice. Thirty BALB/c-nu/nu nude mice (purchased from Shanghai Slack Experimental Animals Co., Ltd., China) were treated according to the following schemes: chemotherapy group $(50 \mu \mathrm{g} / \mathrm{kg}$ paclitaxel intraperitoneal injection), thermo-chemotherapy group $(50 \mu \mathrm{g} /$ $\mathrm{kg}$ paclitaxel intraperitoneal injection with $43^{\circ} \mathrm{C}$ waterbath), wortmannin group (thermo-chemotherapy combined with wortmannin intraperitoneal injection), NAC group (thermochemotherapy combined with NAC intraperitoneal injection) and controls (equal saline intraperitoneal injection without any other treatments). There were 6 nude mice in each group and every nude mouse was treated once a week for 3 weeks. Nude mice were sacrificed 2 days after the last treatment. 

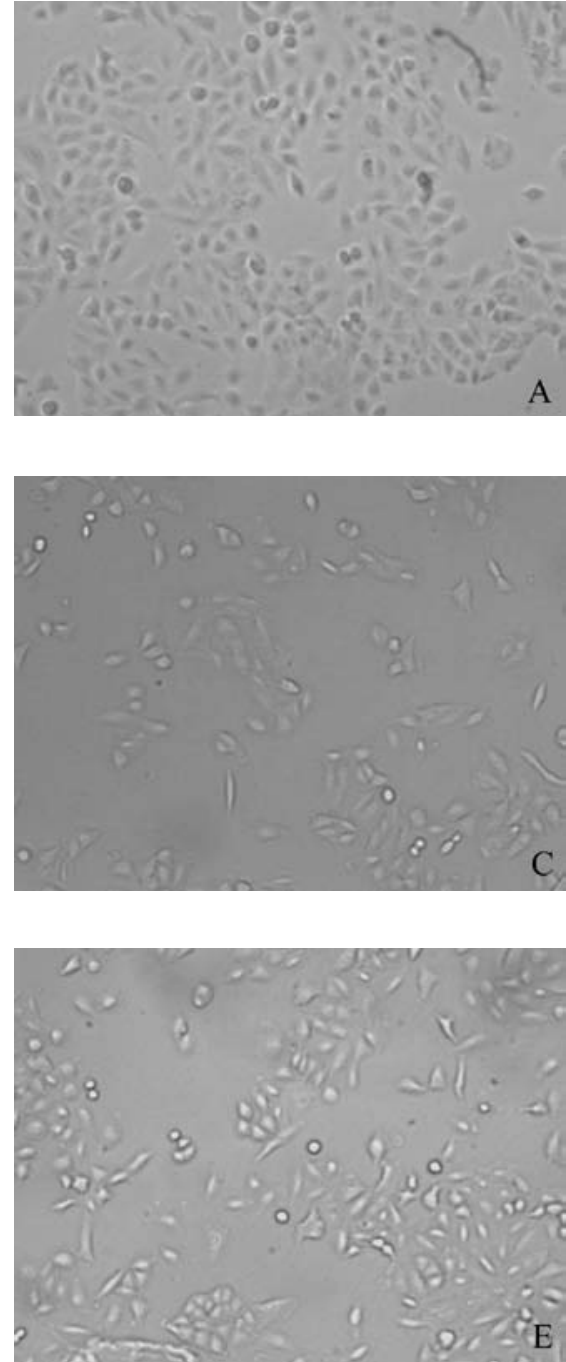

Changes in behavior, eating, defecation and weight were tracked. When grafts were removed, graft inhibition rates were calculated according to the following formula: graft inhibition rates $(\%)=($ graft quality in control group - graft quality in experimental group)/graft quality in control group $\mathrm{x} 100 \%$. The institutional committee for animal research approved these experiments.

Statistical analysis. The software of SPSS 13.0 was employed for data analysis and results are shown as mean \pm SD. Comparisons among groups were analyzed with a one-way ANOVA and LSD method was applied for multiple comparisons. $\mathrm{P}<0.05$ was regarded as significant.

\section{Results}

Cell proliferation rates. A549 cells in control group grew normally in fusiform or polygonal shape. In chemotherapy group, the number of A549 cells became less and many cells were detached from the flask wall. Many cells were in division phase and cell bodies became round and small. In thermo-chemotherapy group, cell morphology was in the shape described as in chemotherapy group, but more cells died. After wortmannin was added, the number of cells
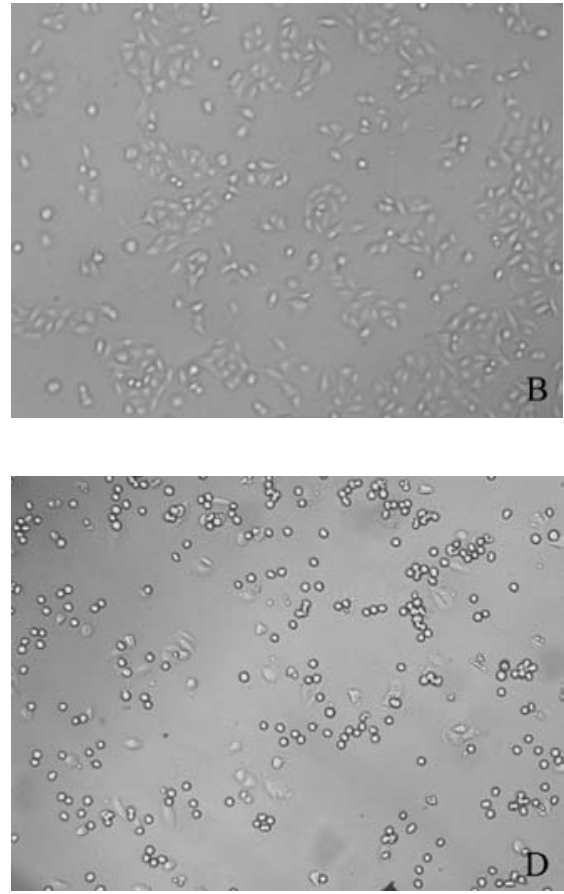

Figure 1. A549 cells in each group. A549 cells were observed by a microscope and at magnification x100. (A) A549 cells in control group were in fusiform or polygonal shape. (B) A549 cells in chemotherapy group became less and many cells detached from the flask wall. (C) A549 cells in thermochemotherapy group were similar to those in chemotherapy group, but more cells died. (D) Increased cell death was seen in A549 cells in wortmannin group. (E) A549 cells in NAC group were alive as in control.

became less but most cells were alive after NAC was added (Fig. 1).

Compared with control group $(100.00 \pm 0.00 \%)$, significantly decreased proliferation rate was detected in the groups treated with chemotherapy $(78.77 \pm 2.38 \%)$ and thermochemotherapy $(56.34 \pm 4.30 \%)(\mathrm{P}<0.05)$ and proliferation rate in thermo-chemotherapy group was significantly lower than in other groups $(\mathrm{P}<0.05)$. Proliferation rate in wortmannin group $(47.40 \pm 0.01 \%)$ was significantly lower than that in thermo-chemotherapy group $(\mathrm{P}<0.05)$ and there was no significant difference between NAC group $(92.65 \pm 0.09 \%)$ and control group $(\mathrm{P}>0.05)$, which indicated that thermotherapy in combination with chemotherapy could inhibit A549 cells growth distinctly and ROS and Akt pathways played a role inhibited by their own inhibitors (Fig. 2).

Changes of intracellular ROS. Cells in control group were red, which showed there was no ROS in them (Fig. 3A); cells in chemotherapy group were green, which indicated ROS in them (Fig. 3B); cells in thermo-chemotherapy group were bright green showing increased ROS (Fig. 3C). Wortmannin had no effect on ROS produced by thermochemotherapy (Fig. 3D), but after NAC was added, cells became red (Fig. 3E). 


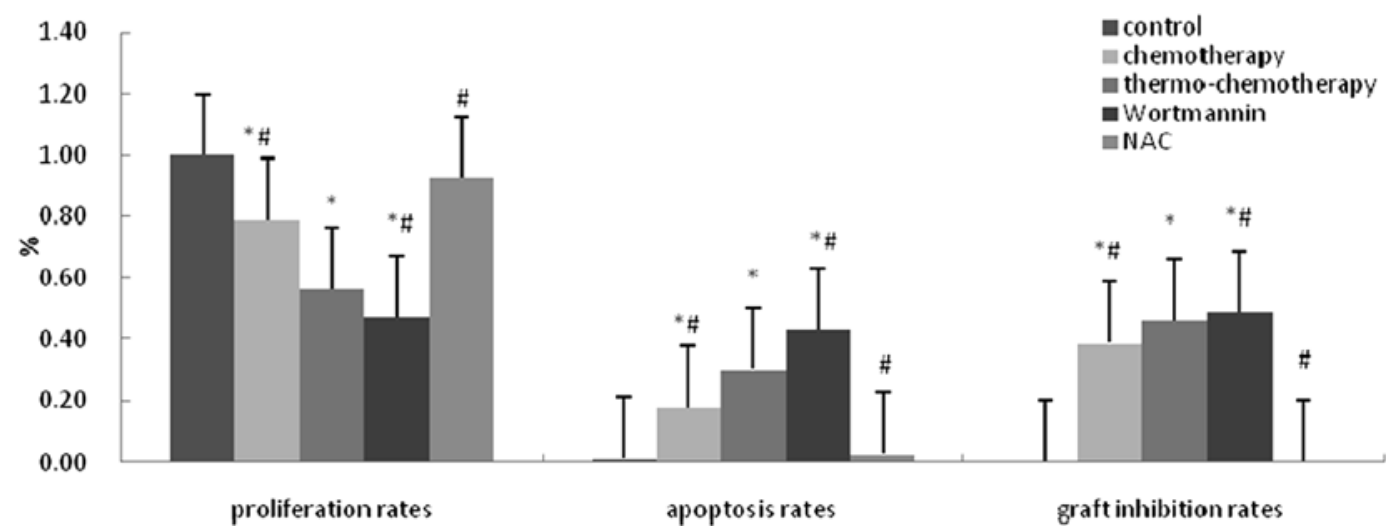

Figure 2. Proliferation rates, apoptosis rates and graft inhibition rates. Proliferation rates were measured by MTT and it decreased significantly in thermo-chemotherapy group compared with control and chemotherapy group. Proliferation rate in wortmannin group was significantly lower than that in thermo-chemotherapy group and there was no significant difference between NAC group and control group. Apoptosis rates were analyzed by FCM and the highest rate was in wortmannin group and that in thermo-chemotherapy group was higher than that in control and chemotherapy group. Graft inhibition rate was higher in thermo-chemotherapy group than in control and chemotherapy group. There was no significance difference between control group and NAC group. ${ }^{*} \mathrm{P}<0.05$ vs. control group, ${ }^{*} \mathrm{P}<0.05$ vs. thermo-chemotherapy group. Thermotherapy in combination with chemotherapy could inhibit A549 cell growth by leading to apoptosis and ROS and Akt pathway played a role, which was confirmed in vivo. Each column represents mean \pm SD value for three repeated independent experiments.
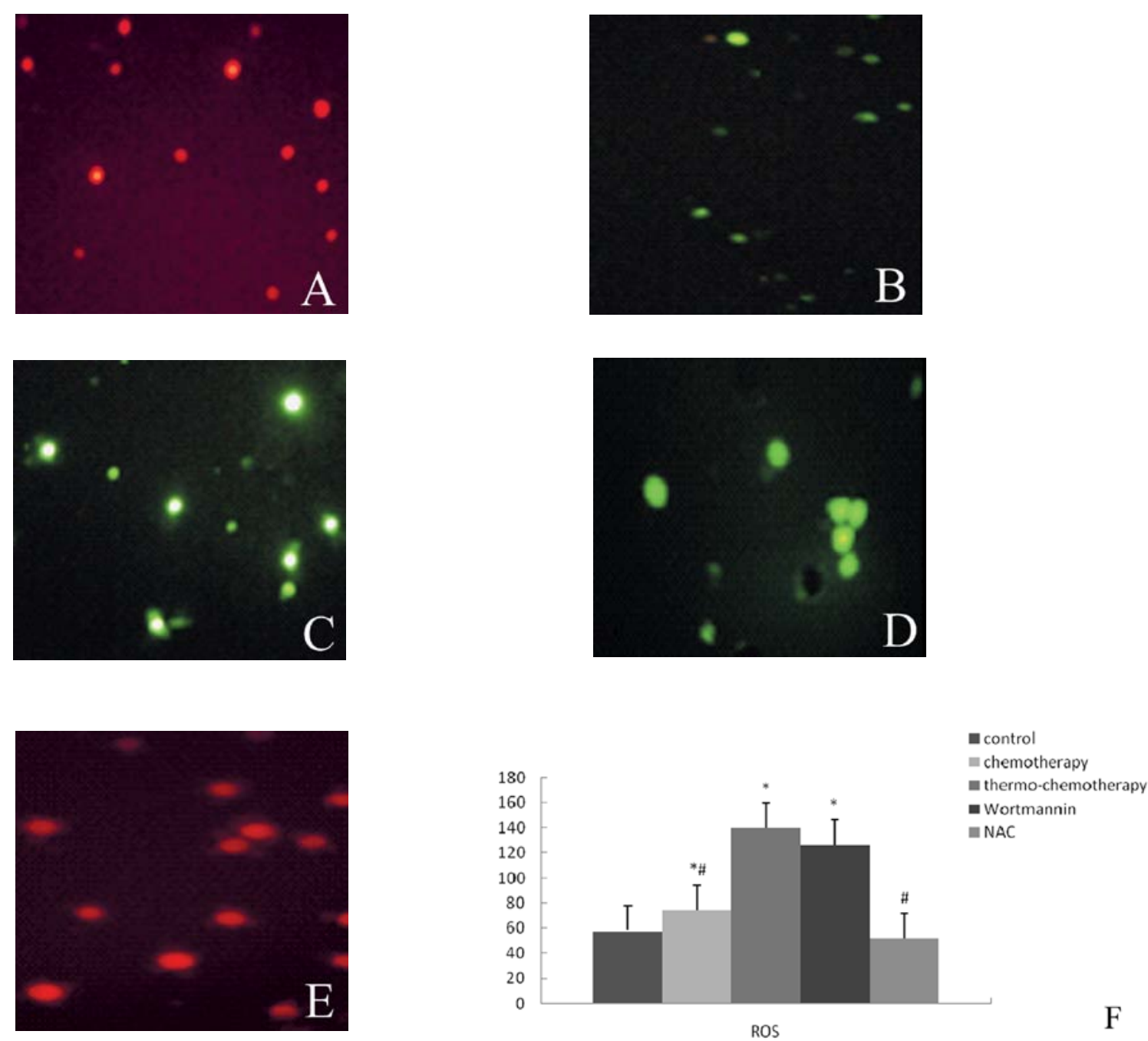

Figure 3. Changes of intracellular ROS. Intracellular ROS changes were detected qualitatively and quantitatively, respectively, by fluorescence microscope and F-4500 fluorospectrophotometer. (A) Cells in control group were red. (B) Cells in chemotherapy group were green. (C) Cells in thermo-chemotherapy group were bright green. (D) Wortmannin had no effect on ROS and (E) NAC inhibits ROS thoroughly to make cells red. (F) ROS production was the highest in thermo-chemotherapy group and NAC decreased its production significantly. Wortmannin has no effect on ROS production. Each column represents mean \pm SD value for three repeated independent experiments. ${ }^{\mathrm{P}}<0.05$ vs. control group; ${ }^{*} \mathrm{P}<0.05$ vs. thermo-chemotherapy group. 

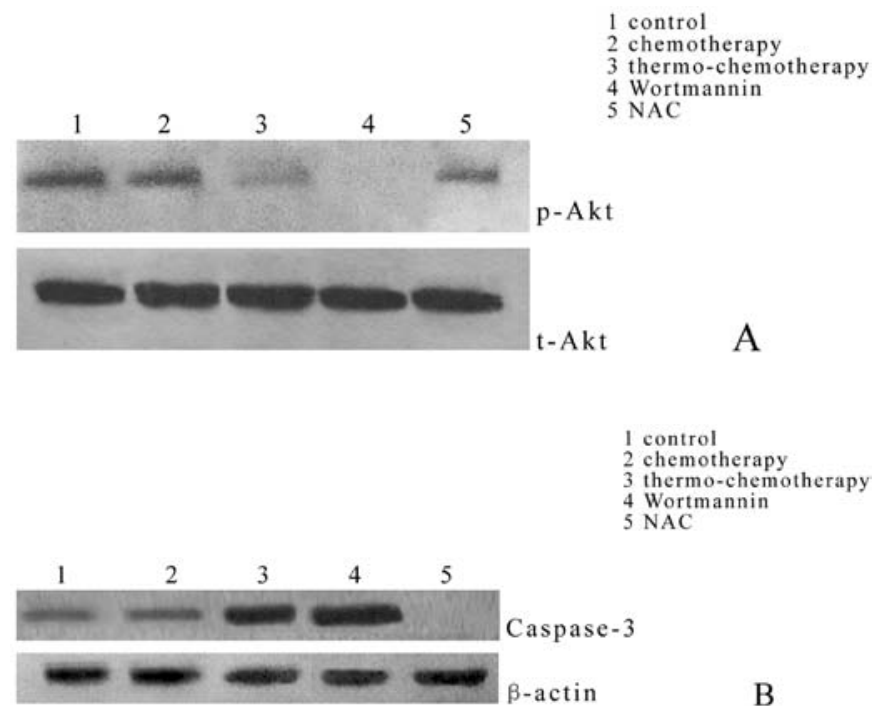

B

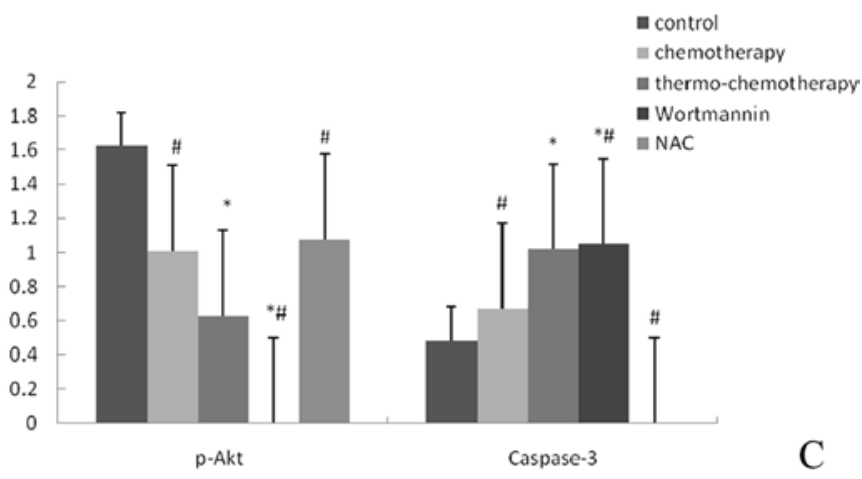

Figure 4. Phosphorylation of Akt and caspase-3 expression in cells. (A) Compared with control group and chemotherapy group, phosphorylation of Akt decreased significantly in thermo-chemotherapy group. NAC increased and wortmannin inhibited it thoroughly. (B) Caspase-3 expression increased in thermo-chemotherapy group compared with control group and chemotherapy group and NAC inhibited its expression completely while wortmannin increased it, which showed that ROS inhibited activation of Akt pathway and activated caspase pathway and Akt pathway was upstream of caspase pathway in thermo-chemotherapy. (C) Western blot analysis of phosphorylation of Akt and caspase-3 expression in cells following different treatment in A549 cells. " $\mathrm{P}<0.05$ vs. control group; ${ }^{\text {}} \mathrm{P}<0.05$ vs. thermochemotherapy group. Semi-quantitative analyses were performed from three independent experiments for t-Akt $/ \beta$-actin.

Compared with thermo-chemotherapy group $(139.93 \pm 37.59 \%)$, significantly decreased ROS production was detected in control group (58.07 $\pm 2 \%$ ), chemotherapy group $(74.40 \pm 3.01 \%)$ and NAC group $(52.11 \pm 1.05 \%)(\mathrm{P}<0.05)$ and wortmannin had no effect on ROS $(126.48 \pm 8.76 \%)(\mathrm{P}>0.05)$, indicating that thermo-chemotherapy induced production of ROS and ROS was upstream of the Akt pathway (Fig. 3F).

Effect of thermo-chemotherapy on phosphorylation of Akt and caspase-3 expression. Compared with thermo-chemotherapy group $(0.63 \pm 0.00 \%)$, Akt phosphorylation in control group $(1.62 \pm 0.03 \%)$ and chemotherapy group $(1.01 \pm 0.41 \%)$ decreased significantly $(\mathrm{P}<0.05)$ and wortmanin completely inhibited Akt phosphorylation $(0.00 \pm 0.00 \%)(\mathrm{P}<0.05)$; but when NAC, the specific inhibitor of ROS, was added, Akt phosphorylation $(1.08 \pm 0.24 \%)$ was significantly higher than that in thermo-chemotherapy group $(\mathrm{P}<0.05)$ (Fig. 4A and $\mathrm{C})$.

Caspase-3 expression in thermo-chemotherapy group $(1.02 \pm 0.02 \%)$ was significantly higher than that in control group $(0.48 \pm 0.11 \%)$ and chemotherapy group $(0.67 \pm 0.02 \%)$ $(\mathrm{P}<0.05)$; after Akt specific inhibitor wortmannin pretreatment, caspase-3 expression $(1.05 \pm 0.09 \%)$ was significantly higher than that in thermo-chemotherapy group $(\mathrm{P}<0.05)$; NAC could inhibited caspase- 3 expression completely $(0.00 \pm 0.00 \%)$ $(\mathrm{P}<0.05)$ (Fig. 4B and $\mathrm{C}$ ) showing that ROS could inhibit activation of Akt pathway and activate the caspase pathway. The Akt pathway was upstream of caspase pathway in thermochemotherapy.

Cell apoptosis. Cell apoptosis rate in control group was $(1.22 \pm 0.18 \%)$ and significantly increased cell apoptosis rates were observed in chemotherapy group $(17.70 \pm 3.23 \%)$ and thermo-chemotherapy group $(30.39 \pm 2.89 \%)(\mathrm{P}<0.05)$. Cell apoptosis rate in thermo-chemotherapy group was significantly higher than that in chemotherapy group $(\mathrm{P}<0.05)$. Compared with thermo-chemotherapy group, cell apoptosis rate in wortmannin group $(43.23 \pm 9.26 \%)$ increased significantly and decreased significantly in NAC group $(2.80 \pm 0.99 \%)(\mathrm{P}<0.05)$ (Fig. 2). Thermotherapy in combination with chemotherapy inhibited A549 cell growth by leading to apoptosis through induction of ROS production and subsequent inhibition of Akt phosphorylation and activation of caspase.

Results of tests in vivo. A549 cells were injected subcutaneously into nude mice and grafts occurred about 1 week later, with round or oval shape. Compared with thermo-chemotherapy group (46.34 $\pm 1.03 \%)$, graft inhibition rate in wortmannin group $(48.97 \pm 0.11 \%)$ increased significantly, and decreased significantly in the control group $(0.00 \pm 0.00 \%)$, chemotherapy group $(38.76 \pm 1.83 \%)$ and NAC group $(0.05 \pm 0.01 \%)(\mathrm{P}<0.05)$, but there was no significant difference between control group and NAC groups ( $\mathrm{P}>0.05)$ (Fig. 2).

Akt phosphorylation in thermo-chemotherapy group $(0.66 \pm 0.06 \%)$ decreased significantly when compared with control group $(1.66 \pm 0.06 \%)(\mathrm{P}<0.05)$ and increased significantly in chemotherapy group $(1.06 \pm 0.04 \%)$ and NAC group $(1.07 \pm 0.02 \%)$ when compared with thermo-chemotherapy group $(\mathrm{P}<0.05)$, but was inhibited completely in wortmannin group $(0.00 \pm 0.00 \%)(\mathrm{P}<0.05)$ (Fig. $5 \mathrm{~A}$ and $\mathrm{C})$.

Caspase-3 expression in thermo-chemotherapy group $(1.01 \pm 0.01 \%)$ was significantly higher than that in control group $(0.49 \pm 0.10 \%)$ and in chemotherapy group $(0.66 \pm 0.03 \%)$ $(\mathrm{P}<0.05)$; Caspase-3 expression in wortmannin group $(1.06 \pm 0.07 \%)$ increased significantly $(\mathrm{P}<0.05)$ and caspase-3 expression in NAC group $(0.00 \pm 0.00 \%)$ was inhibited completely $(\mathrm{P}<0.05)($ Fig. $5 \mathrm{~B}$ and $\mathrm{C})$. All these results in cells were authenticated in vivo.

\section{Discussion}

Thermotherapy is a new treatment of tumors, which plays an important role in comprehensive treatment of tumors. Thermotherapy in combination with chemotherapy is able to improve tumor treatment efficiency (18). Initially thermo- 


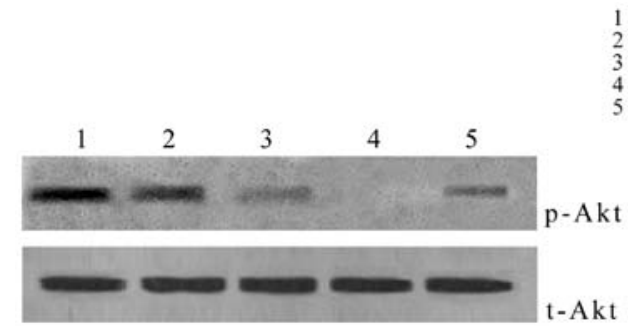

1 control

2 chemotherapy

3 thermo-chemotherapy

4 Wortmannin

\section{A}

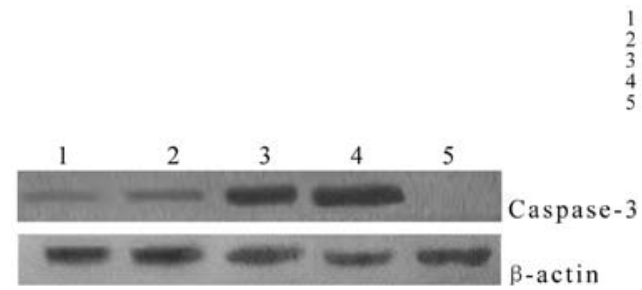

1 control

3 thermo-chemotherap

4 Wortmannin

5 NAC

B

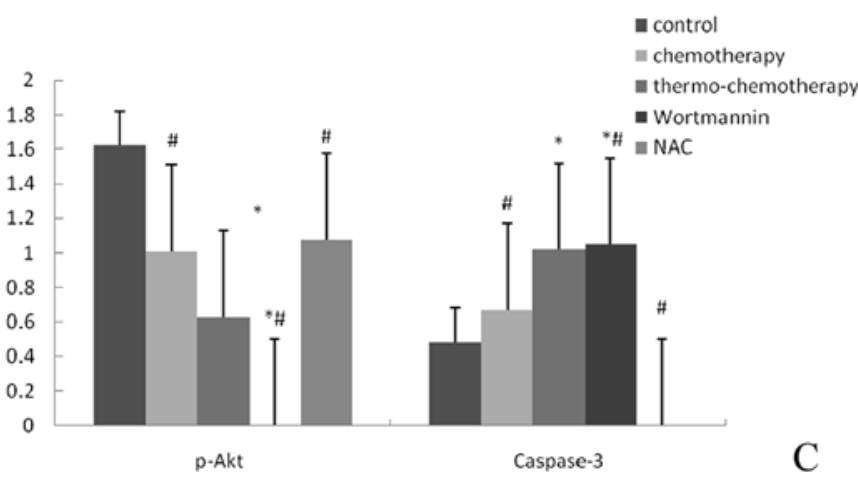

Figure 5. Phosphorylation of Akt and caspase-3 expression in vivo. This figure was confirmed in vivo. (A) Phosphorylation of Akt in thermo-chemotherapy group decreased significantly compared with control group and chemotherapy group. Wortmannin inhibited it thoroughly. (B) Compared with control group and chemotherapy group, caspase- 3 expression increased in thermo-chemotherapy group. NAC could inhibit it completely and it increased in wortmannin group. (C) Western blotting analysis phosphorylation of Akt and caspase-3 expression in cells following different treatment in vivo. ${ }^{~} \mathrm{P}<0.05$ vs. control group; ${ }^{~} \mathrm{P}<0.05$ vs. thermo-chemotherapy group. Semi-quantitative analyses were performed from three independent experiments for $\mathrm{t}-\mathrm{Akt} / \beta$-actin.

therapy was regarded as 'green treatment' by the clinicians (19). In 1990s, some investigators paid attention to the phenomenon of cell apoptosis induced by heat. This study shows that thermotherapy in combination with chemotherapy could increase injury of drugs on tumor cells by increasing ROS production, which leads to Akt activation, and apoptosis of A549 cells through caspase cascade, which was consistent with observation in vivo.

Normally, production and clearance of ROS is in a dynamic balance (20). Cell growth needs some ROS and ROS causes tissue cell apoptosis or necrosis (21). When ROS balance was broken, more ROS would be produced and oxidation stress occurred, which would induce internal $\mathrm{Ca}^{2+}$ flow, unregulating the expression of bax and activating caspase, then leading to cell apoptosis $(22,23)$. ROS was induced in the process of tumor thermotherapy (24). The results of this study show that thermotherapy in combination with drugs would change induction and effect of ROS on tumor cells, which provides a new approach to treat tumors. This study finds that thermotherapy could increase production of intracellular ROS, which is an important factor of apoptosis. It is also found that this induction of ROS caused by thermotherapy could be inhibited by the ROS inhibitor NAC, but not by the PI3K inhibitor, wortmannin (Fig. 3). Therefore, ROS is likely to be upstream of inhibition on Akt pathyway activation.

PI3K (phosphoinositide 3 kinase) is a phosphatidyl kinase and induced tumor cell hyperplasia by activating apoptosisrelated Akt pathway (25). Its anti-apoptosis function may have related to caspase activation. Phosphorylation of Akt could resist apoptosis in chemotherapy and radiotherapy (26). Previous studies (27) have showed that phosphorylation of Akt was increased from normal cells to atypia then to malignant transformation with molecular markers related to loss of apoptosis indicating that Akt extended survival of tumor cells and inhibited apoptosis. Noske et al (28) found that there was overexpression of Akt in 58\% primary ovarian cancer and RNA interference inhibited phosphorylation of Akt to inhibit ovarian cancer cell proliferation. In this study, p-Akt is highly-expressed in A549 cells and heat can decrease levels of Akt phosphorylation. Also, p-Akt could be inhibited by NAC and wortmannin (Figs. 4 and 5). Results of MTT and FCM show that cell proliferation rates decreased and apoptosis rates increased in thermo-chemotherapy group. Therefore, inhibition of thermotherapy on lung tumor cell growth was associated with Akt pathway activation.

In practice, wortmannin could inhibit phosphorylation of Akt both in vivo and in vitro (29). In our study, levels of p-Akt in thermo-chemotherapy group were significantly lower than those in control group and chemotherapy group. Wortmannin completely inhibited phosphorylation of Akt (Figs. 4 and 5). Combined with results of MTT and FCM, cell apoptosis rates in wortmannin group are higher than those in thermo-chemotherapy group, which shows that thermotherapy inhibited Akt pathway activation and NAC activated the Akt pathway. Wortmannin can increase antitumor effects of thermotherapy at the same time.

Caspases are a group of cysteine proteases, which have similar amino acid sequences, and play an important role in cell apoptosis. Caspase family enzymes regulate cell apoptosis. Many apoptosis factors induce apoptosis by caspase-3 mediated signal pathway (30). In this study, heat could induce caspase- 3 activation in A549 cells and NAC could inhibit caspase- 3 expression in heated A549 cells (Figs. 4 and 5 ), which suggests that production of ROS was upstream of caspase-3 activation in A549 cell apoptosis induced by heat. When heat inhibited phosphorylation of Akt, the expression of caspase-3 increased, which shows that inhibition of Akt pathway activation was upstream of caspase- 3 activation.

In summary, thermotherapy could block the cell cycle and improved induction of cell apoptosis (31). Cell apoptosis is one characteristic of cell life and an active death form conducted by genes. Inhibition of PI3K/Akt pathway activation could increase tumor cell apoptosis induced by drugs (32). Cell apoptosis rate in wortmannin group increased. But level of p-Akt increased while cell apoptosis rate decreases after NAC addition, which suggests that ROS inhibited activation of Akt pathway and induced cell apoptosis. Inhibition of caspase- 3 activity or antagonism of its function may inhibit cell apoptosis, indicating that caspase- 3 is essential to cell apoptosis (33). Thus, thermotherapy in combination 
with chemotherapy showed a stronger inhibitory effect than chemotherapy alone on A549 cell growth, probably through induction of ROS production and subsequent inhibition of Akt phosphorylation to activate caspase cascade, which would lead to lung cancer cell apoptosis. All results were confirmed in vivo. These results provide a theoretical basis for thermotherapy clinical practice.

\section{Acknowledgements}

This study is supported by the National Natural Science Foundation of China (nos. 30571552 and 30972457 ).

\section{References}

1. Yin WB, Yu ZH, Xu GZ and Hu YM: Radiation Oncology (Fourth Edition). Peking Union Medical College Press, pp307$321,2008$.

2. Lu H and Chen LB: Hyperthermia combined with other therapies for cancer therapy. Postgrad Med J 17: 458-460, 2004.

3. Verwaal VJ, van Tinteren H, Ruth SV and Zoetmulder FA: Toxicity of cytoreductive surgery and hyperthermic intraperitoneal chemotherapy. J Surg Oncol 85: 61-67, 2004.

4. Bakhshandeh A, Bruns I, Traynor A, et al: Ifosfamide, carboplatin and etoposide combined with 41.8 degrees $\mathrm{C}$ whole body hyperthermia for malignant pleural mesothelioma. Lung Cancer 39: 339-345, 2003.

5. Wang JH, Yao MZ, Zhang ZL, Zhang YH, Wang YG and Liu XY: HSF1 blockade-induced tumor thermotolerance abolishment is mediated by JNK-dependent Caspase-3 activation. Biochem Biophys Res Commun 321: 736-745, 2004.

6. Pletjushkina OY and Fetisova EK: Hydrogen peroxide produced inside mitochondria takes part in cell-to-cell transmission of apoptotic signal. Biochemistry 71: 60-67, 2006.

7. Cheng Y, Chang LW and Tsou TC: Mitogen-activated protein kinases mediate arsenic-induced down-regulation of survivin in human lung adenocarcinoma cells. Arch Toxicol 80: 310-318, 2006.

8. Hamdi M, Kool J, Cornelissen-Steijger P, et al: DNA damage in transcribed genes induces apoptosis via the JNK pathway and the JNK-phosphatase MKP-1. Oncogene 24: 7135-7144, 2005.

9. Vizio B, Poli G, Chiarpotto E and Biasi F: 4-hydroxynonenal and TGF-beta1 concur in inducing antiproliferative effects on the CaCo-2 human colon adenocarcinoma cell line. Biofactors 24: 237-246, 2005.

10. Wen KC, Shih IC, Hu JC, Liao ST, Su TW and Chiang HM: Inhibitory effects of terminalia catappa on UVB-induced photodamage in fibroblast cell line. Evid Based Complement Alternat Med 2011: 904532, 2011.

11. Shi XY, Cai XJ, Lei JX, Cao FJ, Pan DF and Chen P: Reversal effect of PI-3K/Akt pathway inhibitor LY294002 on multidrug resistance of ovarian cancer cell line A2780/Taxol. Ai Zheng 27: 343-347, 2008 (In Chinese).

12. Manning BD and Cantley LC: AKT/PKB signaling: navigating downstream. Cell 129: 1261-1274, 2007.

13. Wang J, Miao LJ, Wu YM, Wu YJ and Wang XC: Expression of AKT2, cyclin D1, and MMP-9 and their correlations to clinicopathologic features of non-small cell Lung cancer. Ai Zheng 25: 69-72, 2006 (In Chinese).

14. Zhuang QY, Chen XG, Dong ZQ, Liu JH and Ye ZQ: Effects of rapamycin on prostate cancer PC-3 cells. Ai Zheng 28: 851-855, 2009 (In Chinese).

15. Lee MJ, Chen HM, Tzang BS, Lin CW, Wang CJ, Liu JY and Kao SH: Ocimum gratissimum aqueous extract protects $\mathrm{H} 9 \mathrm{c} 2$ myocardiac cells from $\mathrm{H}(2) \mathrm{O}(2)$-induced cell apoptosis through Akt signalling. Evid Based Complement Alternat Med 2011: 578060, 2011.
16. Johnson GL and Lapadat R: Mitogen-activated protein kinase pathways mediated by ERK, JNK and p38 protein kinases. Science 298: 1911-1912, 2002.

17. Gao S, Wang L, Wu WD and Zhou F: Synergistic effect of thermotherapy in combination with chemotherapy on lung tumor A549 cells growth through activation of c-Jun N-terminal kinase and inhibition of heat shock protein70 expression. Wei Sheng Yan Jiu 37: 529-532, 2008 (In Chinese).

18. Patel S, Sanborn RE and Thomas CR Jr: Definitive chemoradiotherapy for non-small cell lung cancer with N2 disease. Thorac Surg Clin 18: 393-401, 2008.

19. Hiraoka M, Masunaga S, Nishimura Y, et al: Regional hyperthermia combined with radiotherapy in the treatment of lung cancers. Int J Radiat Oncol Biol Phys 22: 1009-1014, 1992.

20. Yan W, Arai A, Aoki M, Ichijo H and Miura O: ASK1 is activated by arsenic trioxide in leukemic cells through accumulation of reactive oxygen species and may play a negative role in induction of apoptosis. Biochem Biophys Res Commun 355: 1038-1044, 2007.

21. Alexandre J, Batteux F, Nicco C, et al: Accumulation of hydrogen peroxide is an early and crucial step for Paclitaxel-induced tumor cell death both in vitro and in vivo. Int J Cancer 1: 41-48, 2006.

22. Jo PG, Choi YK and Choi CY: Cloning and mRNA expression of antioxidant enzymes in the pacific oyster, crassostrea gigas in response to cadmium exposure. Comp Biochem Physiol C Toxicol Pharmacol 147: 460-469, 2008.

23. Cho SD, $\mathrm{Li} \mathrm{G}, \mathrm{Hu} \mathrm{H}$, et al: Involvement of c-Jun N-terminal kinase in G2/M arrest and caspase-mediated apoptosis induced by sulforaphane in DU145 prostate tumor cells. Nutr Cancer 52: 213-224, 2005.

24. Hirano H, Tabuchi Y, Kondo T, et al: Analysis of gene expression in apoptosis of human lymphoma U937 cells induced by heat shock and the effects of alpha-phenyl N-tert-butylnitrone (PBN) and its derivatives. Apoptosis 10: 331-340, 2005.

25. Foster K, Wang Y, Zhou D and Wright C: Dependence on PI3K/ Akt signaling for malignant rhabdoid tumor cell survival. Cancer Chemother Pharmacol 63: 783-791, 2009.

26. Chin Y R and Toker A: Function of Akt/PKB signaling to cell motility, invasion and the tumor stroma in cancer. Cell Signal 21: 470-476, 2009

27. Kobayashi I, Semba S, Mat suda Y, Kuroda Y and Yokozaki H: Significance of Akt phosphorylation on tumor growth and vascular endothelial growth factor expression in human gastric carcinoma. Pathobiology 73: 8-17, 2006.

28. Noske A, Kaszubiak A, Weichert W, et al: Specific inhibition of AKT2 by RNA interference results in reduction of ovarian cancer cell proliferation: increased expression of AKT in advanced ovarian cancer. Cancer Lett 246: 190-200, 2007.

29. Tsurutani J, West KA, Sayyah J, Gills JJ and Dennis PA: Inhibition of the phosphatidylinositol 3-kinase/Akt/mammalian target of rapamycin pathway but not the MEK/ERK pathway attenuates laminin-mediated small cell lung cancer cellular survival and resistance to imatinib mesylate or chemotherapy. Cancer Res 65: 8423-8432, 2005.

30. Okun I, Balakin KV, Tkachenko SE and Ivachtchenko AV: Caspase activity modulators as anticancer agents. Anticancer Agents Med Chem 8: 322-341, 2008.

31. Vertrees RA, Das GC, Popov VL, et al: Synergistic interaction of hyperthermia and gemcitabine in lung cancer. Cancer Biol Ther 4: $1144-1153,2005$.

32. Dogra C, Changotra H, Wergedal JE and Kumar A: Regulation of phosphatidylinositol 3 kinase (PI3K)/Akt and nuclear factor kappa B signaling pathways in dystrophin-deficient skeletal muscle in response to mechanical stretch. J Cell Physiol 208: 575-585, 2006

33. Zheng XW, Li Y, Tang FA, Ma J, Zheng PY and Lu GF: In vivo antitumor effect of canstatin gene on human esophageal carcinoma xenografts in nude mice. Ai Zheng 28: 350-355, 2009 (In Chinese). 